\title{
Un deseo que permanece deseo. Antonio Di Benedetto y la potencia de la imaginación
}

\author{
A desire that remains desire. Antonio Di Benedetto \\ and the Power of Imagination \\ Um desejo que permanece desejo. Antonio $\mathrm{Di}$ \\ Benedetto e a potência da imaginação
}

\section{Rafael Arce}

IHUCSO-CONICET-UNL, ARGENTINA

Profesor de literatura argentina en la Universidad Nacional del Litoral.

Investigador adjunto del Consejo Nacional de Investigaciones

Científicas y Técnicas. Doctor en Humanidades con Mención en

Literatura por la Universidad Nacional de Rosario. Autor de fuan

fosé Saer: la felicidad de la novela (UNL Ediciones, Santa Fe, 2017);

"Lejanos, extraños, visitantes. Los animales nietzscheanos de Antonio

Di Benedetto" (Centro de Estudios de Teoría y Crítica Literaria,

Rosario, 2017, en coautoría con Laura Soledad Romero); "Una

reflexión sobre el realismo literario. Cuentos Claros de Antonio Di

Benedetto" (Universidad Santiago de Compostela, 2017); "Nathalie

Sarraute frente al nouveau roman. Una heterodoxa genealogía de

la novela moderna" (Asociación de Francesistas de la Universidad

Española, 2016). Correo electrónico: rafael.arce@gmail.com

Artículo de investigación

Documento accesible en línea desde la siguiente dirección: http://revistas.javeriana.edu.co

doi:10.11144/Javeriana.c122-43.dpda 


\section{Resumen}

El artículo propone una lectura de El pentágono, primera novela del escritor argentino Antonio Di Benedetto. Esta lectura intenta superar las clasificaciones genéricas que se dividen entre el realismo literario y el fantástico, pero también discute la interpretación meramente antirrealista de la novela. Para ello, utiliza el concepto de imaginación y propone una hipótesis que se pretende generalizable al resto de la obra.

Palabras clave: Di Benedetto; imaginación; antirrealismo; fantástico

\section{Abstract}

This paper proposes a reading of El pentágono, the first novel by the Argentine writer Antonio Di Benedetto. This reading tries to overcome the generic classifications that are divided between literary realism and the fantasy genre. But it also discusses the purely antirealistic interpretation of the novel. To this end, it uses the concept of imagination and proposes a hypothesis that intends to be generalizable across the rest of the work.

Keywords: Di Benedetto; imagination; anti-realism; fantasy genre

\section{Resumo}

$\mathrm{O}$ artículo propõe uma leitura de El pentágono, primeiro romance do escritor argentino Antonio Di Benedetto. Esta leitura visa superar as classificações genéricas que se dividem entre realismo literário e fantástico. Mas, também discute a interpretação meramente antirrealista do romance. Para isso, utiliza o conceito de imaginação e propõe uma hipótese que se pretende generalizável ao resto da obra.

Palavras-chave: Di Benedetto; imaginação; antirrealismo; fantástico 
DE LA OBRA de un autor, la crítica y la historia literaria suelen subrayar zonas de importancia y momentos de intensidad. De la obra narrativa de Antonio Di Benedetto (Mendoza, 1922 - Buenos Aires, 1986), es habitual destacar su mejor novela, Zama, ${ }^{1}$ publicada en 1956 ; las dos novelas con las que forma una trilogía, El silenciero (1964) y Los suicidas (1969); algunos de sus mejores libros de relatos: Mundo animal (1953), Cuentos claros (1957) y El cariño de los tontos (1961); y algunos relatos puntuales: "Caballo en el salitral", "Aballay", "Declinación y Ángel", "El abandono y la pasividad". Además de su célebre trilogía, Di Benedetto publicó su última novela poco antes de su muerte, Sombras nada más (1984), escrita en el exilio y rubricada por el patetismo del cierre de una obra.

En contraste, su primera novela, El pentágono $(1955),{ }^{2}$ ha sido poco estudiada. La misma lleva por subtítulo Novela en forma de cuentos. En la solapa de sus libros reeditados (que llevó adelante de modo íntegro la editorial Adriana Hidalgo), la incomodidad genérica se traduce en una coartada retórica: se nos dice que Di Benedetto es "autor de novelas y libros de relatos", a continuación de lo cual se los enumera en orden cronológico, evitando así tener que denominar a su primera obra. Pero si tenemos en cuenta el armado de los Cuentos completos (2002), la ausencia de cualquier relato que forme parte de la novela corrobora, por lo menos por la negativa, su pertenencia genérica. Esta distinción, realizada de modo tácito por la editorial a cargo de su obra completa, no elimina la incomodidad que $E l$ pentágono plantea a la clasificación.

En el prólogo a su novela Cinco, Sergio Chejfec afirma que El pentágono es "el relato más misterioso de nuestra literatura" (9). Lo misterioso incluye su inestabilidad genérica (llamarlo "relato" permite suspender la alternativa cuento/novela), pero la afirmación de Chejfec pretende ir más lejos: apunta a la extrañeza del texto mismo. Lo raro, lo extraño, lo misterioso: adjetivos con los que la crítica suele caracterizar la obra del narrador mendocino. Pero la cualidad sobresaliente de El pentágono es que se trata de un texto extraño incluso en el interior de una obra extraña: inclasificable, refractario a su

1 Juan José Saer escribió el prólogo a una reedición de la novela publicada en 1973: "Zama es superior a la mayor parte de las novelas que se han escrito en lengua española en los últimos treinta años, pero ninguna buena novela latinoamericana es superior a Zama" (Saer 44). Para Premat es "su obra mayor" (Premat, Héroes 102).

2 Mundo animal (1953), relatos, es el primer libro de Di Benedetto. Sin embargo, es posible que nuestra novela sea la primera obra en ser escrita: "El proyecto de El pentágono, libro escrito a fines de los cuarenta y quizás antes de Mundo animal..." (Premat, Héroes 101). 
contexto de producción, hermético; el primer relato de Di Benedetto es un verdadero experimento, inédito para la época y el lugar en donde fue escrito, pero también inédito para su obra misma.

Algunas filiaciones permiten a la historia literaria ubicar a Di Benedetto en dos coordenadas en cierto sentido contradictorias: el género fantástico y la narrativa existencialista. El fantástico, por el interés que suscitó en el narrador mendocino la ficción de Borges (Néspolo 61-75). El existencialismo, por el diálogo, en ocasiones polémico, con la obra de Ernesto Sábato, así como su propia lectura de Sartre y de Camus (Néspolo 177-186). Estas coordenadas solo para situar el origen de la obra en lo que Chejfec llama "nuestra literatura", es decir, la argentina. Las dos coordenadas pueden muy esquemáticamente coincidir con la división genérica de su obra: el fantástico es una clave de lectura apta para abordar la mayoría de sus cuentos; el existencialismo, por su parte, es una filiación que establecen especialmente sus novelas. La historia literaria señala, además, una característica que enrarece estas dos coordenadas del contexto de producción: el hecho de que Di Benedetto escribiera en una ciudad provinciana del interior argentino, alejado de los grandes centros de consagración como Buenos Aires o las ciudades europeas (Prieto 350). Para un escritor mendocino de comienzos de los años cincuenta, cuando el auge de estéticas realistas ${ }^{3}$ comienza a socavar la hegemonía del fantástico borgiano, consagrado en la década del cuarenta, lo esperable era una literatura regionalista y costumbrista (Prieto 350-353). Di Benedetto rechaza esta alternativa y construye su universo narrativo con las grandes claves que le proporciona su época: Borges, el gran realismo de la novela, pero también la literatura europea, Camus, Kafka, el nouveau roman. ${ }^{4}$

3 En 1953 aparece la revista Contorno. Encabezada por los hermanos David e Ismael Viñas, Contorno se presenta como la oposición crítica de Sur, proponiendo una lectura política de la literatura desde una perspectiva de izquierda, disputando el lugar central de la obra borgiana y colocando en el centro del canon la de Roberto Arlt, revisando la historia literaria como el despliegue de un programa liberal burgués, incorporando teorías como el marxismo, la fenomenología sartreana y el psicoanálisis y, finalmente, practicando en ocasiones una narrativa realista de crítica social, considerada por ellos mismos como contraria al "esteticismo" borgiano. Cfr. Prieto (321-331).

4 "Sin duda ciertos textos de Di Benedetto comparten características con corrientes literarias existentes, como las vanguardias de los sesenta (tono existencial de la experimentación, cuestionamiento del género novela, heterogeneidad y fragmentación, ruptura como programa de escritura), o mucho le deben a algunas lecturas (Borges, Pirandello, Camus), pero lo que se impone es una impresión de 'coincidencia': con el Nouveau roman, con Beckett, con el pensamiento crítico de Blanchot" (Premat, "Un pentágono" 295). 
Estas dos coordenadas, con las que simplificamos un planteamiento mucho más complejo, permiten establecer parámetros clasificatorios al interior de la obra, pero, nuevamente, dejan afuera El pentágono: por eso decíamos más arriba que el "misterio" del que habla Chejfec es también propio de un relato excéntrico dentro de una obra ella misma excéntrica. Para ubicar este relato en el sistema de la literatura argentina, hacen falta otras claves. La crítica las ha señalado y solamente son operativas para ubicar El pentágono, pero no resultan útiles para el resto de la obra. También son dos: la primera, la relación que este texto podría tener con la obra de Macedonio Fernández; la segunda, el carácter de precursor de una novela mucho más célebre: Rayuela de Cortázar. La relación con Macedonio estriba sobre todo en el carácter de "narración abstracta" de $E l$ pentágono: una novela cuya historia es solamente su posibilidad de ser escrita y las reflexiones metaficcionales que tal posibilidad conlleva (Verdevoye 336). Lo examinaremos más abajo. En cuanto a Rayuela, la propuesta de una "novela en forma de cuentos" habilita la posibilidad de considerar cierta autonomía en los capítulos de El pentágono y, por lo tanto, una propuesta lúdica en la que el orden de lectura podría ser alterado: en efecto, si los cuentos pueden ser leídos por separado, quizás la novela pueda recorrerse alterando el orden de los capítulos en cualquier sentido (Néspolo 67). Examinaremos también esta hipótesis.

Coordenadas de la obra completa (fantástico, existencialismo) y coordenadas de El pentágono (Fernández, Cortázar): nuestra lectura las tendrá en cuenta, pero tratará sin embargo de ceñir, en la medida de lo posible, la singularidad de la novela, aquello que la vuelve irreductible a cualquier filiación. Singularidad que, no obstante, y a pesar de su extrañeza en el interior del corpus de autor, permitiría proponer una hipótesis generalizable al resto de la obra.

Volvamos al prólogo de Chejfec. Vale la pena la cita en extenso:

"No se puede saber si es verdad." [sic] Así comienza el relato más misterioso de nuestra literatura. Cuando escribió El Pentágono, a Antonio Di Benedetto no le interesaba tanto la verdad como comprobación (el encadenamiento de hechos que habla de una sucesión, la jerarquía de razones que sostiene el mundo), sino la verdad como estatuto sentimental. Sin tener recuerdo personal de ellos, para mí no hay emblema más adecuado de los años 5o. Las obras literarias de aquel entonces supieron contribuir a ese ambiente; después de esos años la verdad abandonaría el interior de los personajes. Ambientes donde se mezclan la nostalgia y lo irreal, el deseo y la frustración. La literatura argentina posterior optó abrumadoramente por representar una versión práctica de la realidad. Práctica en el sentido de útil y también de portable. (9) 
Volveremos sobre este fructífero pasaje. Por el momento, señalemos la contextualización espacio-temporal a la que alude Chejfec: esa literatura argentina posterior se refiere al auge de la narrativa realista y su correlato teórico-crítico representado por la irrupción de la revista Contorno. La expresión corresponde a la "Introducción al pentágono", que forma parte de la novela. Esta introducción coloca ya el relato en un nivel ficcional: un narrador contará cómo se escribió lo que el lector leerá. La introducción explica el modo en el que está concebida estructuralmente esta peculiar novela en forma de cuentos, pero además señala cuál es su motivación: la decepción amorosa, motivo recurrente en la obra. Parece relativamente sencillo leer la primera frase como una proposición antirrealista: "No puede saberse si es verdad" (Chejfec altera levemente la cita), como introducción a la explicitación del carácter ficcional de los relatos, es susceptible de interpretarse como una problematización del realismo literario, género por antonomasia de la forma novelesca en Argentina desde comienzos de siglo hasta finales de los cuarenta. ${ }^{5}$ La extrañeza de cada uno de los cuentos o capítulos, que puede estabilizarse normalizando algunos rasgos genéricos aislados (fantástico, maravilloso, policial, alegórico), permite retrospectivamente leer esa primera frase como una propuesta antirrealista que, al no renegar de la forma novelesca, posee innegables ribetes macedonianos. Di Benedetto elige la novela (género "serio", género del existencialismo y del realismo literario, del costumbrismo de la literatura regionalista y de la literatura comprometida), pero niega desde el comienzo todo realismo, colocando la historia en el orden de lo inverificable y de lo inverosímil.

Ahora bien, lejos de caer en esa interpretación fácil, incluso obvia, Chejfec afirma, por el contrario, que a Di Benedetto le interesa la verdad. A fines de los noventa, en plena descomposición posmodernista, hablar de verdad parece un notorio anacronismo: solo puede comprenderse si se considera el carácter programáticamente moderno de un escritor como Chejfec. En vez de leer una posición antirrealista negadora de toda verdad, Chejfec insiste con su afirmación y con la validez de su estatuto. Pero esta verdad no es la del verosímil realista, sea literario, narrativo o discursivo en general (el encadenamiento de los hechos y la jerarquía de razones que sostienen un mundo racional y verdadero), sino una verdad del sentimiento o, como diríamos hoy en sintonía con ciertas líneas filosóficas contemporáneas, una verdad del afecto.

5 De ahí que el programa antirrealista borgiano, así como la vanguardia martinfierrista de la década del veinte en la cual se inscribe, se manifieste de modo espectacular en el rechazo del género novelesco y en la adopción de la "forma breve" del cuento o el relato. 
Examinemos la estructura de la novela. La misma consta de la "Introducción al pentágono" y de cuatro partes: tres "épocas" interrumpidas por un "interludio". La primera época es la especulativa; la segunda, la crítica; la tercera, la de la realidad. Esta tripartición se explica en la introducción, a partir de la historia sentimental:

No puede saberse si es verdad. Cuentan que él se enamoró de una muchacha, de menos años y más fina, con apellido, muy inclinada al baile. Pero como él no tenía más que cultura y eso ni siquiera hermosea el cuerpo de un hombre, fue sensato y no intentó nada. De esta manera, claro, no enmudecía la vocecita, esa vocecita que hace sufrir.

Como las cosas no podían quedarse así, tuvo que buscarse una solución. Y esa solución fue burlarse de sí mismo, darse argumentos, suponer que si se casaba con ella, irremisiblemente sería burlado. Para que el remedio no quedara en el mortero, sacaba todo eso del cerebro y lo ponía en relatos, cuentos, los primeros de su pluma que le parecieron viables. (25)

La crítica subraya a menudo el carácter fragmentario y evanescente del sujeto en la obra del mendocino (Premat, Héroes 100-101; Néspolo 42). También, la reticencia y el pudor que caracteriza a sus narradores (Schvartzman). En la introducción, la tercera persona parece ocultar al protagonista: ese escritor enamorado no sería otro que el que escribe la introducción misma, despersonalizándose al narrar como si él fuera otro. En la renuncia del personaje a intentar la seducción, se establece una oposición prototípica: la "vida" de la muchacha (juventud, apellido, baile, belleza) se opone a la "cultura" del protagonista (madurez, escritura, fealdad, falta de alcurnia). Esa renuncia a la acción se justifica con una "suposición": el protagonista imagina que si se casa con la joven, sufrirá una infidelidad. Esa hipótesis masoquista (el primer párrafo nos dice que se niega a hacer callar a "esa vocecita que hace sufrir") se transforma en literatura: los cuentos que se agrupan en la primera época de la novela, la especulativa.

La introducción nos cuenta también que el protagonista se convierte en escritor y se casa con otra mujer, enamorado, pero que "nada tenía que ver con la vocecita" (26), es decir, con la conciencia de ese deseo que permanece deseo y que, por lo tanto, hace sufrir (y, también, gozar de modo masoquista). Se nos dice además que la elección de esta mujer es "menos pretenciosa" (26): ¿'menos alcurnia, menos belleza, menos vida? No se nos aclara. Pero, irónicamente, los miedos del protagonista se vuelven reales: la mujer minus- 
valorada termina siéndole infiel. Estos son los cuentos que se agruparán en la tercera época, la de la realidad.

Ahora bien, la introducción sigue con ese estilo conjetural, "cuentan de él", "dicen", como si este narrador recogiera testimonios de oídas:

Lo que se le ve hacer es una nueva combinación con terminología geométrica, que no debe estar muy próxima al rigor de lo que es verdad en geometría. Al parecer, él parte de la idea literaria de triángulo amoroso y deriva hacia otra figura, suponiendo que hay dos triángulos, aunque hace desaparecer uno de los ángulos porque en los dos triángulos es el mismo, es decir, él. (27)

La "idea literaria" es un lugar común sentimental: el triángulo, metafórico, se vuelve literal, se transforma en una figura geométrica cabal. Pero hay dos triángulos: el especulativo (formado por el protagonista, Laura y Rolando Fortuna) y el real (formado por el protagonista, Barbarita y Orlando Sabino). En la especulación mental, el protagonista suprime las líneas que van de cada amante a él, estableciendo una sola línea entre ellos dos: los triángulos se convierten entonces en otra figura geométrica, un pentágono. Continúa el introductor: "Es admisible, sin embargo, que la descomposición en elementos constitutivos haya sucedido a la síntesis, primera aparición, elaborada por operarios subconscientes" (29). El pentágono, la figura completa, "aparece", entonces, como un todo, en el cual especulación y experiencia vienen confundidas: lo que se imagina acontece, lo que se teme se vuelve real. Aquello que se agrupa en "épocas", siguiendo el nivel de realidad de los cuentos (enamoramiento de una mujer, casamiento con otra, desengaño), se da como un "todo" en la aparición de la figura, es decir, de la historia de la novela, en la cual los límites que separan lo mental de lo corporal, lo soñado de lo vivido, lo imaginado de lo real, serán puestos en cuestión.

Ahora bien, si lo primero que se presenta es el todo de la síntesis, y la escritura consiste en la descomposición de los elementos, el procedimiento de este narrador tendría una prosapia borgiano-macedoniana: borgiana, porque trabaja reduciendo la complejidad y pluralidad de lo real, aislando una serie de rasgos principales; ${ }^{6}$ macedoniana, porque esa operación pro-

6 Nos referimos a la noción borgiana de "postulación de la realidad": "Yo aconsejaría esta hipótesis: la imprecisión es tolerable o verosímil en la literatura, porque a ella propendemos siempre en la realidad. La simplificación conceptual de estados complejos es muchas veces una operación instantánea. El hecho mismo de percibir, de atender, es 
duce, por yuxtaposición de fragmentos (y no por composición de un todo orgánico), una novela puramente abstracta, en la cual la "aventura" no es otra que el itinerario de la conciencia (esa "vocecita que hace sufrir", una conciencia desdichada, masoquista, dislocada). Esto significa que la separación imaginación/realidad es posterior a la experiencia originaria de las cosas, en la cual lo que está racionalmente separado se piensa no obstante unido, se experimenta conectado por relaciones no causales y no lógicas, como las del sueño.

La estructura en tres épocas no hace más que corroborar esta hipótesis de la novela como aventura de la conciencia narradora: la división evoca los pasos argumentativos de ciertos textos filosóficos o, con más precisión, los avatares de la dialéctica. El interludio, por su parte, interfiere el esquema filosófico aludiendo a una tentativa organización musical. No es la única: en la introducción, refiriéndose al carácter tragicómico de la historia, se propone la imagen de una "ópera bufa" (30).

Examinemos el primer cuento del volumen, o el primer capítulo de la "época especulativa". Citemos el comienzo: "Al contarle, le contó: '...y soñé que volaba'. Entonces me nació esto de que yo también había soñado que volaba. Pero no sé cuándo. En realidad, no está nada claro" (37). Veremos más abajo cuál es la situación en la que se produce la escucha del protagonista. Subrayemos ahora lo siguiente: el primer cuento es el relato de la escucha de un relato, más precisamente el relato de un sueño (como en una sesión con el psicoanalista). El narrador cuenta lo que escuchó contar (enfatizando de un modo casi infantil, propio del estilo del autor, en la repetición del mismo verbo): ese relato es el de un sueño, que evoca en el protagonista una experiencia, la de haber soñado alguna vez lo mismo. Continúa el segundo párrafo:

Tal vez no fue un sueño, sino que efectivamente yo puedo hacerlo o es que alguna vez podía y lo hice. Posiblemente esto corresponda a mi primera edad. Puede ser un juego de niño que solo yo sabía jugar. No lo sé. Pero sí puedo decir, aun ahora y en todo momento, que mi cuerpo posee a ese respecto algo así como una experiencia. (37)

de orden selectivo: toda atención, toda fijación de nuestra conciencia, comporta una deliberada omisión de lo no interesante. [...] Nuestro vivir es una serie de adaptaciones, vale decir, una educación del olvido" (Borges 255). 
Sartre afirma que la memoria no distingue entre percepción e imaginación. ${ }^{7}$ El vuelo pudo ser real o imaginario, pero la reviviscencia (la escucha del relato ocasiona en el narrador no solamente un recuerdo, sino además algo así como un déjà vu: "me nació esto...") lo actualiza como indistinguible: la experiencia del cuerpo es real, como es real para el psicoanálisis lo que el durmiente experimenta en el sueño. Justamente, el narrador ubica sin precisión el sueño o la experiencia en la temprana infancia: si quisiéramos volver ese recuerdo verosímil, podríamos decir que, o bien el narrador soñó que volaba, o bien era un niño que jugaba a volar ("Era un vuelo casi a ras de la tierra...", 37). Se sabe: el niño juega en serio, el "como si" lúdico, como el de la ficción, es para el niño algo real, que solamente la elaboración posterior, adulta y racional, separa como fantasía. Lo veíamos en la introducción: la síntesis es lo originario, pero la síntesis no es la consecuencia de una superación, lo que se depura después de la tesis y la antítesis, sino la coalescencia de la vigilia y el sueño, de la realidad y la fantasía. No lo claro y lo distinto (lo cartesiano), sino lo oscuro y lo indistinto: lo que no puede separarse. Lo llamaremos, con Sartre, lo imaginario.

No daremos, todavía, una definición estricta de imaginario y de imaginación. ${ }^{8}$ Bastará con decir por ahora que, para Sartre, la imaginación no es meramente una facultad de la conciencia, sino más bien un modo de pensamiento: un pensamiento irreflexivo, prelógico, anterior al pensamiento sistemático. En nuestro análisis del comienzo de la novela, la infancia del narrador aparece como la experiencia mezclada de lo onírico y lo real, lo fantástico y lo verosímil. La crítica ha señalado la importancia de la infancia en la obra de Di Benedetto. En general, se la ha interpretado como figuración de la inocencia, la indigencia, el desamparo, la irracionalidad (Feld; Giordano). Nosotros entendemos que la infancia es el mundo en el cual una conciencia imaginante se da ciertos objetos. La infancia puede evocar la inocencia o la irracionalidad, pero alude fundamentalmente a un tipo de pensamiento, preracional y pre-cartesiano, el de la imaginación. De modo que la infancia no es

7 "Es que, como ya hemos visto, si la conciencia inmediata sabe distinguir por naturaleza el objeto en imagen del objeto real presente, la memoria confunde estos dos tipos de existencia porque los objetos reales y los objetos irreales se le aparecen a título de recuerdo, es decir, como pasados" (Sartre 183).

8 Solamente por operatividad, aclaremos el sentido más corriente de la distinción. Imaginación es un sustantivo que refiere a la facultad de la conciencia de producir imágenes. Imaginario es un adjetivo que significa aproximadamente "irreal" o "ficticio". Usado como sustantivo (lo imaginario) refiere al dominio o espacio de la imaginación (Belinsky 12-13). 
algo del orden de la carencia (falta de culpabilidad, de racionalidad, de amparo), sino más bien algo del orden de la potencia. Trataremos de comprender cómo trabaja esta potencia de la imaginación en la obra de Di Benedetto.

La historia transcurre en una oficina y lo que escucha el narrador es la conversación de dos compañeros. El ambiente es kafkiano, las mesas escritorios están demasiado juntas; los cuerpos, si bien no desaparecen individualmente, forman parte de un "nuevo cuerpo". Para el narrador, el problema es la separación del propio pensamiento,

... porque se amasa con el pensamiento de los otros o más bien se infiltra mi pensamiento en el de los otros y el de los otros se infiltra en el mío y esto se convierte en algo untuoso, como una atmósfera de manteca, que nos envuelve y nos impregna. (38-39)

Es decir que el primer relato que compone la figura interroga no solo la problemática de la distinción entre percibir e imaginar (a partir de la indistinción en la memoria), sino de modo fundamental el problema del estatuto de la propia conciencia: ¿cómo separar mi pensamiento del pensamiento de los otros?

Esta imposibilidad se traduce también a lo corporal: el narrador siente que no puede moverse sin que los otros se muevan con él. La dependencia física no solamente se refiere a la repetición alienante del trabajo oficinesco: alude asimismo a la estereotipia del comportamiento social. La vida cotidiana pone en evidencia el "tipo" del empleado público, con sus tics y sus miserias. Lo que obsede al protagonista es no poder diferenciarse de los otros: el problema de separar el propio cuerpo físico y el propio pensamiento atañe a la cuestión de la individualidad. La posibilidad de la diferencia se introduce con la aparición de Laura, la amada. Poseer a Laura es tener lo que los otros dos no tienen, por más que puedan tener mujeres con otros nombres, o incluso con el mismo nombre (41). Recordemos la introducción: la elección de Laura es "pretenciosa". De modo que la diferencia social (empleado público que anhela a una mujer de buena clase) abre la posibilidad de una individualidad. Esta diferencia se introduce con el dos del amor, que rompería el tres de la relación social: el triángulo. En la introducción, el triángulo aparecía como la invasión de lo público en la intimidad de lo privado: lo que parece preocupar al protagonista, en la versión del introductor de la historia (recordemos que puede ser el mismo sujeto desdoblado), no es tanto que su amada le sea infiel (en la imaginación, Laura; en la realidad, Barbarita), como que los demás lo sepan (esos colectivos anónimos que divulgan las versiones de la historia). 
Otro lugar común: al marido que sufre una infidelidad le duele menos el engaño propiamente dicho que su difusión pública.

El triángulo, entonces, figura en principio la impersonalidad social. El narrador fantasea con una liberación (con una diferenciación y una individualización) situándola en la posesión de Laura. La fantasía es finalmente decepcionada: "Aquí estoy, en la oficina. Mis brazos, con los brazos de ellos. Mis manos, amada, aligeradas por tus manos. Y tú, más allá, más allá de la oficina, sin mis manos, con tus manos en las manos de alguien ajeno a la oficina..." (42). La infidelidad supuesta vuelve a introducir la figura de tres líneas ahí donde la recta de los amantes prometía romperla: el triángulo amoroso repite el triángulo social, lo íntimo duplica lo público. Los dos triángulos, el que el narrador forma con sus dos compañeros de oficina y el que forma con Laura y su amante, se cierran en un pentágono.

El segundo cuento posee ribetes de fantástico. El narrador pide la mano de Laura: el padre de ella es afinador de pianos y la madre costurera. Viven pobremente en el contrabajo de la joven. Después del viaje de bodas, Santiago compra un departamento a sus suegros para que Laura pueda seguir dedicándose a la música sin tener que dejar en la calle a su familia. Siguen una serie de torpezas del protagonista que desembocan en la ruptura de la pareja. Años después, el narrador va a verla tocar en un concierto. Después la sigue y descubre que ella vive en el contrabajo con un muchacho. La acusa, entonces, de haberlo abandonado por otro hombre. Ella le dice que no, que lo abandonó por el contrabajo y que Rolando vive con ella porque también ama el contrabajo.

La estructura es la misma: un triángulo (Laura y sus padres) interrumpido por una línea recta (Santiago y Laura) que vuelve a ser triángulo en el desenlace (Santiago, Laura y Rolando). En este caso, el primer triángulo es edípico: la aparición del novio con pretensiones rompe la armonía familiar. El encierro en el contrabajo da paso al encierro en la infeliz vida de pareja: mientras en el primer relato el narrador no podía salir de su triángulo-cárcel, aquí libera a su amada para volver a encerrarla en otra figura, la del esquema sádico. En efecto, lo que el narrador, con pudor, llama "torpezas", son en realidad ejercicios de crueldad con la amada: "Pero yo estaba en trance de herir. [...] Sin embargo, yo no era malo" (47). En la introducción interpretamos un cierto masoquismo en la imaginación paranoica del protagonista. En este cuento, el sadismo es su reverso, la respuesta histérica a la posesión del objeto. Recordemos que estos dos cuentos pertenecen a la época especulativa, en la cual el protagonista se inventa historias que lo hagan sufrir y sirvan de coartada para la inacción: no intentar nada con Laura. Esta imaginación es 
paranoica y perversa: no puede haber cumplimiento del deseo (casamiento) sin decepción (infidelidad), ni historia feliz sin venganza psicológica simétrica: puesto que Laura es inalcanzable en la realidad, el protagonista imagina poseerla para poder, a su vez, hacerla sufrir.

Este cuento puede ser interpretado como fantástico o bien como alegórico. En la primera clave, la vacilación propia del género descansa en la ambigüedad del punto de vista: Santiago percibe, quizás de modo distorsionado, aquello que se opone a su vida de pareja. Su amada habita el contrabajo con sus padres y después con Rolando, pero no puede convivir con él: Santiago traduce esas dos armonías de pareja como una vida literal en el contrabajo, hogar que solo a él expulsa. Su neurosis se vuelve delirio: sus imposibilidades se convierten en impedimentos exteriores a su voluntad. En la segunda clave, la dura vida en el contrabajo es una metáfora de la sufrida vida del artista. La vida de pareja se opone a la vida bohemia: "Tú amas la promiscuidad en el contrabajo" le dice Santiago a Laura (48). El arte, por otro lado, es una vocación de juventud, por eso no se opone a la vida de Laura con sus padres, sino a la vida adulta con su marido. Rolando habita con Laura el contrabajo porque comparte el modo de vida bohemio, lo que rechaza Santiago.

Los dos cuentos poseen su autonomía. El primero es una parábola de tintes kafkianos sobre la indistinción social y la posible salida amorosa que se presenta finalmente como tramposa, puesto que repite el triángulo. El segundo puede ser leído en clave fantástica o alegórica. Pero, de modo simultáneo, ambos repiten un esquema. Estructuralmente, son variaciones de un mismo tema. Todos los relatos de la época especulativa lo reiteran, alternando esquemas con ribetes genéricos, en ocasiones apenas reconocibles: melodrama, policial, fantástico, maravilloso.

Ahora bien, los dos cuentos pueden llevarnos también en una dirección interpretativa de corte psicoanalítico. El triángulo (social, familiar) figura el orden simbólico: es decir, la ley paterna, que por definición es castradora. Lo que busca el protagonista en la figura fantasmal de Laura es la restitución del vínculo dual, originario, con el cuerpo materno. En efecto, y tal como lo pensó Jacques Lacan, este vínculo originario es del orden de lo imaginario. ${ }^{9}$

"Para ello, la relación polar por la que la imagen especular (de la relación narcisista) está ligada como unificante al conjunto de elementos imaginarios llamado del cuerpo fragmentado, proporciona una pareja que no está solamente preparada por una conveniencia natural de desarrollo y de estructura para servir de homólogo a la relación simbólica Madre-Niño. La pareja imaginaria del estadio del espejo, por lo que manifiesta de contranatura, si hay que 
La liberación del triángulo es la tentativa de escapar al orden simbólico, lo que en Di Benedetto se figura además en su particular sintaxis y léxico: una extenuación de la gramaticalidad que acerca su prosa a un balbuceo infantil, a una lengua pre-simbólica, hecha menos de signos que de imágenes.

Volvamos al uso de los géneros. Di Benedetto utiliza el policial de un modo heterodoxo, minimalista, como en su novela Los suicidas. En "La suicida asesinada", el juego de la fantasía masoquista se complica, pues se da al interior del relato mismo, de un modo tan sutil que el lector debe descifrarla. El triángulo se compone en el comienzo al modo de la repetición doble de una frase de Laura: "Yo me voy a morir de amor" le dice al narrador (51). Lo hace en tres momentos claves: durante el noviazgo, dos años después de casados y la noche anterior a su muerte. El narrador no sabe si Laura se suicidó o fue asesinada: la policía, después de la investigación, tampoco. Una tarde que va a llevarle flores al cementerio descubre a un desconocido ante su tumba. Otra vez, en el tranvía, descubre al mismo hombre llevando el anillo de casado que el protagonista, supuestamente, había perdido en una noche de borrachera con su mujer. Lo sigue por las calles, hasta que el desconocido lo espera sentado ante la mesa de un café, dispuesto a encararlo: ahí se termina el relato. El narrador pretende deducir que es el asesino de su esposa y ladrón del anillo, pero el lector, que leyó los otros dos relatos y la introducción, puede comprender que esa explicación se la da el protagonista para engañarse ante la evidencia: su esposa tenía un amante, a quien dio el anillo luego de quitárselo al marido aquella noche, y no la mató nadie, sino que se suicidó. La frase patética dicha tres veces ("Yo me voy a morir de amor") adquiere un matiz sarcástico: en efecto, se suicida por amor, pero por estar atrapada en un triángulo, del que no encuentra otra salida más que la muerte.

El uso minimalista, casi paródico, del policial, se repite en "El desesperado manso", cuento que comienza con el asesinato de Rolando, el sempiterno amante de Laura en la época especulativa. El hecho, lejos de aliviar al protagonista, desemboca en una situación grotesca: conoce al hermano de Rolando, que le asegura que se vengará de los asesinos y, además, completará todas las cosas que Rolando dejó inconclusas. Una de ellas: amar a Laura. En este relato, el pentágono se articula con el tópico del doble (o tal vez el tópico del doble sea intrínseco a la formulación del pentágono).

referirla a una prematuración específica del nacimiento en el hombre, resulta ser adecuada para dar al triángulo imaginario la base que la relación simbólica pueda en cierto modo recubrir" (Lacan 528). 
La época se cierra con dos relatos maravillosos. En el primero, el narrador se entera de la infidelidad de Laura luego de su muerte. Violando el deseo de su hija, Laurita (tenemos de nuevo el triángulo edípico), hurga en sus cosas, descubriendo el nombre de Rolando Fortuna. Sin explicar cómo, el narrador nos revela que se vuelve inmortal y funda un club de inmortales, del que es presidente. La vida eterna muestra, como en "El inmortal" de Borges, una característica sobresaliente: el tedio, la futilidad. Un día pide admisión un nuevo miembro: Rolando Fortuna. Como en cada uno de los relatos, el narrador no solo sufre la infidelidad, sino que se ve obligado cada vez a encontrarse con el amante de su mujer. Cada dolor se redobla en un regodeo masoquista, que a veces adquiere el carácter grotesco de una tragicomedia o, como se dice en la introducción, de un "chiste amargo" (30). Rolando se gana la amistad de los miembros del club y el protagonista termina yéndose derrotado.

En el último de la serie, el narrador es una araña que observa con atención la enfermedad y agonía de Rolando, esperando el momento de su muerte para reemplazarlo en el lecho matrimonial junto a Laura. Esta interpolación es muy del autor: en su primer libro de cuentos, Mundo animal, a menudo los narradores sufren metamorfosis animales. Los planes de la araña, una vez más, son defraudados: Rolando, que guardaba un revólver bajo la almohada (el protagonista pensaba que para darse una muerte digna), finalmente dispara a Laura en la cabeza. La araña se arroja a su brazo para picarlo e impedirlo, pero termina destrozada, de modo que los tres mueren, o al menos la pareja muere y el protagonista sobrevive mutilado (en términos psicoanalíticos, castrado), lo que también es una constante en las fantasías de desmembramiento en Mundo animal.

En este punto se impone plantear una pregunta: la distinción en tres épocas de $E l$ pentágono ¿es meramente paródica? ¿Cuál es el sentido de este proceso que atraviesa lo especulativo, lo crítico y lo real? Vimos que la introducción colocaba de entrada la historia en el plano de la imaginación. Ahora bien, dentro de este plano, se suceden las tres épocas. Esto significa que la novela de Di Benedetto no niega simplemente el realismo literario. El movimiento es más matizado. La época crítica consistirá en tres relatos en los cuales el matrimonio con Bárbara colocará a Laura en un plano idealizado, irreal. La época de la realidad, finalmente, repetirá la fatalidad de la infidelidad, en la cual lo especulativo se habrá vuelto cierto. ¿Diremos que en el interior de esta historia "puramente ficcional" (como obliga a concebirla la introducción) lo que se nos cuenta es el naufragio de la imaginación y, en consecuencia, de las ilusiones desmentidas por la realidad? Nuestra hipótesis va 
en un sentido diferente. Creemos, por el contrario, que las etapas crítica y de la realidad son necesarias para la afirmación del carácter imaginario de la etapa especulativa. Lo que narra la novela es el modo en el que la imaginación, como conciencia pre-reflexiva, se apodera de la trayectoria de una conciencia que debe recorrer el camino esperable de la racionalidad humana y adulta. Al repetir en la realidad lo que solo era especulación, al volverse lo especulativo profético, la novela plantea que la crítica de la imaginación no desemboca en ninguna realidad concreta, en la cual finalmente poder disolver lo imaginario como quimera o fantasía infantil. Pero esta trayectoria que hace fracasar el itinerario de la conciencia moderna ${ }^{10}$ no es un avatar que deba evaluarse como trágico. Esta lectura de la conciencia que fracasa es habitual en la crítica dibenedettiana: "Es decir que la novela articula el paso de la fantasía a la realidad (lo imaginado se cumple), como una fatalidad de la infidelidad y la pérdida, como una compensación ante una situación sin salida en la relación amorosa" (Premat 296).

O, de otro modo, suele interpretarse la fantasía de Di Benedetto en términos negativos: como encarnación de los miedos o las fobias del sujeto (Varela 132). Nosotros pensamos, por el contrario, que no hay fatalidad ni compensación ni explicación negativa: el narrador quiere producir lo imaginario como tal. O, dicho en términos menos antropomorfos, la novela afirma no el desencanto de la imaginación frente a la realidad, sino la potencia de la imaginación para intensificar una experiencia que no quiere saber nada con distinguir lo real de lo irreal. Como lo dice Sartre:

La imagen se da, pues, como "más verdadera que la naturaleza", en el sentido en que se podría decir de un retrato particularmente significativo que es más verdadero que su modelo. Pero no es más que una imagen. Por otra parte, la conciencia no afirma nada sobre su naturaleza real: ¿es una construcción realizada sobre datos actuales, una ilusión, un recuerdo particularmente vivo? Cuando la imagen está presente, no decidimos (56, énfasis nuestro).

10 "En la fórmula con que el aristotelismo medieval recoge esa función mediadora de la imaginación ('nihil potest horno intelligere sine phantasmate'), la homología entre fantasía y experiencia todavía es perfectamente evidente. Pero con Descartes y el nacimiento de la ciencia moderna la función de la fantasía es asumida por el nuevo sujeto del conocimiento [...] Entre el nuevo ego y el mundo corpóreo, entre res cogitans y res extensa, no hace falta ninguna mediación. [...] De sujeto de la experiencia, el fantasma se transforma en el sujeto de la alienación mental, de las visiones y de los fenómenos mágicos, es decir, de todo lo que queda excluido de la experiencia auténtica" (Agamben 26-27). 
Si la imaginación es una conciencia pre-reflexiva, propia de la infancia, no deja de ser, en este sentido, una utopía de la ficción: el escritor, adulto, es fatalmente racional. Sin embargo, se ha dicho, la obra de Di Benedetto explora obsesivamente las formas de lo irracional y los mecanismos de lo pulsional. Nosotros interpretamos esta búsqueda en términos de una fenomenología de la imaginación. ¿Cuál es la experiencia de El pentágono (y, quizás, de toda la obra de Di Benedetto)? La restitución del movimiento por el cual una conciencia racional se metamorfosea en conciencia opaca, indistinta, recuperando la coalescencia de lo que originariamente no está separado: percepción, pensamiento, sensación, imagen, recuerdo, sueño. Por eso el planteamiento de la novela es una parodia de los pasos críticos de la filosofía cartesiana: no se trata de separar el sueño de la realidad, lo claro y distinto de lo oscuro e indistinto, lo verdadero de lo falso, sino de volver a enmarañarlo todo. Ese enmarañamiento es el trabajoso arrancamiento de una conciencia imaginante, que es el modo en el que el narrador dibenedettiano concibe la novela y el relato. ${ }^{11}$ Por supuesto, esta clave admite su variante psicoanalítica: la búsqueda de la novela es la de restituir la experiencia corporal que antecede a la castración simbólica. Ese dos que es uno ("Aunque yo forme con ellos un cuerpo de seis brazos entremezclados, formo con Laura otro cuerpo de cuatro brazos", 41) es el del niño no completamente desprendido de la madre: el horizonte de un retorno al orden de lo imaginario, a un pasado arcaico y mítico, que la novela transmuta en la fábula de la amada inalcanzable. ${ }^{12} \mathrm{De}$ ahí el carácter abstracto del planteo: el narrador es pura conciencia, puro espíritu, porque de lo que se trata es de la liberación de un cuerpo atrapado por la organización triangular del orden simbólico (el lenguaje, pero también la cultura), duplicado y redoblado en el pentágono (el doble triángulo, el doble cierre, simbólico y cultural, privado y público, familiar y social).

De lo que se trata en la novela es entonces del nacimiento de una conciencia imaginante. Un nacimiento que requiere un esfuerzo y un trabajo porque la conciencia "natural" es la cartesiana. Esta naturalidad es tal que a todo relato se le plantea siempre la pregunta por su relación con el realismo. Este realismo es

11 "Una conciencia perceptiva se aparece como pasividad. Por el contrario, una conciencia imaginante se da a sí misma como imaginante, es decir, como una espontaneidad que produce y conserva el objeto en imagen" (Sartre 26).

12 "El primer momento es el de la relación dual, pre-edípica, en la que el niño sólo se encuentra con un alter ego, la madre, y vive esta relación bajo el modo de la fascinación imaginaria propia del estadio del espejo; es decir, sin poder tomar nunca, ni respecto del otro ni de sí mismo, la distancia que impondría la presencia de un tercero" (Belinsky 50). 
el de un mundo racional, cuyos narradores no solo otorgan sentido a una serie de hechos encadenados lógico-causalmente, sino que además dependen de un aparato óptico-perceptivo: el que permite una descripción de personajes y espacios inherente a lo novelesco. El pentágono, como primera novela del autor, tiene algo de programático: realiza la genealogía de esta conciencia imaginante que define un cierto modo de concebir la narración y al narrador. A partir de entonces, en novelas si se quiere mejores (Zama, como su obra maestra, pero también El silenciero y Los suicidas, con su laconismo y austeridad radicales), la conciencia imaginante será más sutil, menos espectacular, más inasible. De modo que coincidimos con Premat: El pentágono constituye un programa de la obra futura (Héroes 100-101). Pero no acordamos con sus motivos: no se trata de que en esta primera novela se planteen los temas fundamentales de su narrativa (por su puesto, se los plantea). Lo que se propone (y es esto lo fundamental) es la genealogía del narrador dibenedettiano, la trayectoria lenta y trabajosa (las épocas que fatalmente hay que atravesar) que transforman una conciencia cartesiana en conciencia imaginante.

Veamos la época crítica. ¿Por qué es necesaria? En principio, porque es imperativo para el narrador poner distancia entre su conciencia y la imagen de Laura. Es habitual oponer imaginación a percepción. ${ }^{13}$ En la percepción, la conciencia se da un objeto por la facultad de la atención. Por el contrario, la conciencia imaginante, para serlo, debe dejarse llevar por una especie de atención flotante o falta de atención: no va ella hacia el objeto, sino que deja que el objeto venga a ella. Se deja llevar. Cuando es capturada por la imagen, se hunde en ella, es decir, cae bajo su fascinación (Sartre 65). El narrador de El pentágono está, en efecto, fascinado por la imagen de Laura. Esta fascinación es la que explica su insistencia, su repetirse cíclico en cada relato, la metamorfosis del mismo fantasma en una fábula diferente. ${ }^{14}$ Para conjurar esa fascinación, para que el narrador no se pierda en un mundo de sueños (lo cual puede ser interpretado en clave realista: para que no se vuelva loco, algo que nos sugieren los comentarios malévolos que recoge el introductor), se hace imperativo restituir la atención. Restitución que tiene su correlato en la historia: Santiago decide dejar a Laura en un mundo de fantasía y emprende, al

13 Cfr. Bachelard (9-29) y Sartre (20-22). Bachelard y Sartre recogen, de todos modos, una oposición filosófica que se remonta a Platón, pasa por Descartes y llega hasta la fenomenología.

14 "... las historias narradas en los relatos que componen El pentágono, por su carácter repetitivo e inverosímil, carecen de peso, mientras que sí cuenta la historia de la escritura de esos textos..." (Premat, Héores 101). Nosotros tratamos de demostrar lo contrario: cada una de esas historias, así como su organización en épocas, tiene su peso específico, inseparable de la ficción de la escritura. 
casarse con una mujer más acorde a su condición social, una acción pragmática, razonable, "realista". Esta es la época crítica: el momento en el cual la atención corroe la fascinación. La crítica es, en efecto, y más allá de lo paródico, un momento kantiano: se trata de ponerle límites a la imaginación, subordinarla al entendimiento. Su matrimonio con Barbarita es un exorcismo destinado a conjurar la fascinación: "Todo es posible, depende de ti. Me encontraste en la edad precisa: desesperado, confuso. Era una desesperación la mía y otra desesperación, tal vez, la tuya" (103). Las palabras son muy precisas: Santiago estaba "desesperado", "confuso"; es decir, hundido en la imagen de Laura, sin poder distinguir la realidad de la fantasía. El encuentro con Barbarita es una decisión de volver a la realidad, haciendo la crítica de su época especulativa (lo que es también un distanciamiento respecto de sus fantasías juveniles). Pero esta crítica no significará negar lo imaginario: por el contrario, la distancia permitirá al narrador liberarse de su fascinación (o de su obsesión, en clave realista) y, de ese modo, conservar la "pureza" de lo imaginario en tanto que tal. En la época crítica, Laura se vuelve imaginaria: el narrador pone distancia con su imagen y la coloca en un plano del cual él mismo se ausenta. De ese modo, no solo el objeto se hunde en su imagen, sino que, lo que es quizás más importante, el sujeto se constituye en un mundo real. La realización del mundo es una consecuencia de la irrealización de lo imaginario: "Lo irreal está producido fuera del mundo por una conciencia que queda en el mundo y el hombre imagina porque es trascendentalmente libre" (Sartre 239).

Volveremos sobre esta condición de la libertad trascendental del hombre. Laura es producida fuera del mundo por una conciencia narradora que se queda en el mundo: madura, se vuelve racional, se casa, forma un hogar, se integra en la sociedad. En efecto, si toda la novela fuera una sola época especulativa, la imagen no sería tal, puesto que no tendría un sujeto constituido en un mundo real ante el cual aparecer como imagen. Así continúa Santiago su monólogo-interpelación:

¿Para qué me cierras los ojos? ¿Por qué prefieres que duerma? ¿Para que no piense en ella? ¿Sabes tú si pienso en ella?

$[\ldots]$

Pero tal vez no. Es mejor que sepas, que no sólo yo sepa que también en mi vida hay algo limpio, que mi cara sucia se mira en un espejo de limpia luna. (103)

Otra vez algo del orden de la histeria o incluso del sadismo: Santiago quiere que Barbarita sepa acerca de Laura. Quiere sentir sus celos, quiere que comprenda la conservación intocada de lo imaginario. 
Nótese cómo nuestro recorrido de lectura ha puesto en cuestión la supuesta autonomía de los cuentos: nuestra argumentación nos ha llevado a explicar el encadenamiento necesario de cada una de las épocas, con lo cual la yuxtaposición de fragmentos autónomos ha dado paso a una estructura novelesca anómala, heterogénea y extraña, pero no menos férrea. En este sentido, no puede llamar la atención que el comienzo de la época crítica retome, anafóricamente, el comienzo de la época especulativa: "Esta vez, por fortuna, no puedo dudar. Fue en sueños: lo sé absolutamente. Si no, se me quedaría en la cabeza, dormida pero presente, esa idea de que yo puedo cantar" (97).

La primera remisión anafórica es casi rítmica, cuasi-rima: antes se trataba de la idea de que el narrador "podía volar" y ahora es la idea de que "puede cantar". La duda anterior respecto del sueño se transforma aquí en certeza: "esta vez" (el adverbio remite anafóricamente a la vez anterior, al comienzo de la época especulativa) el narrador lo sabe "absolutamente". Más aún: lo sabe "por fortuna", lo cual alude sarcásticamente al imaginario rival (Rolando Fortuna; en la época de la realidad, el amante de Barbarita se llamará Orlando, es decir, será un anagrama del rival imaginario). El comienzo de la época crítica es entonces una separación tajante entre el sueño y la vigilia, un nacimiento de la conciencia cartesiana, que puede distinguir y afirmar con certeza y claridad. Esto tiene su correlato en la historia: Santiago está acostado con Barbarita dormida a su lado, es el momento en el cual se plantea el problema del sueño y la realidad. En el próximo capítulo (a esta altura de nuestro análisis podemos dejar de llamarlos "cuentos"), del cual extrajimos la cita anterior, seguirán en la misma escena (" ¿Por qué prefieres que duerma?"). Hay en esta época una cierta inmovilidad, una acción puramente contemplativa. El narrador tematiza con toda nitidez el carácter imaginario de Laura y sabe perfectamente que es la presencia de Barbarita la que convierte a la otra en fantasma, es decir, en una ausencia que posee una densidad y una fuerza que la vuelven una cierta presencia:

Yo la sentía visible y su ternura posiblemente hubiera sido palpable. [...] Ella era algo estatuario, aunque cálido y viviente. [...] Y podía verla, pero en una distancia de lugar y también en una distancia de tiempo. Laura era la que fue, siendo asimismo la que es en mí. (97)

Para Sartre, el objeto que se da una conciencia imaginante tiene la paradójica cualidad de estar presente como ausencia. En la imagen, el objeto está allí (puesto que tengo una imagen del mismo), pero como ausente (puesto que 
no está allí). Escapa, por lo tanto, a la alternativa metafísica presencia/ausencia. Esta paradoja la expresa la última oración de la cita: el verbo en pasado corresponde al objeto, mientras que el verbo en presente se refiere al sujeto. Laura "fue" porque, al separarla del mundo real, la experiencia la ubica en un cierto pasado: el "delirio" fue superado por la racionalidad. Pero, de modo simultáneo, Laura sigue siendo de una cierta manera: "la que es en mî", su modo de existencia es un ser presente ("es") que depende del sujeto, que no solo la ha constituido en ese proceso (en esa época especulativa que termina con la crítica), sino que además se ha constituido a sí mismo. Dice Sartre:

La característica de Pedro [o de Laura en nuestro texto] no es ser nointuitivo, como podríamos creer, sino ser "intuitivo-ausente", dado ausente a la intuición. Se puede decir en este sentido que la imagen encierra una determinada nada. Su objeto no es un simple retrato, sino que se afirma; pero al afirmarse se destruye. Por muy viva, por muy fuerte, por muy sensible que sea una imagen, da su objeto como no siendo. (25-26)

Volvamos a la cita de la novela: Laura es "algo estatuario, aunque cálido y viviente". Estatuario, porque es imaginaria, porque es inaccesible, incluso sagrada; pero también es cálida y viviente porque la imagen es, o puede ser, más intensa que la sensación. La presencia física de Barbarita durmiendo a su lado es menos intensa que el recuerdo del delirio que tuvo, en el pasado, a la amada como objeto.

La época de la realidad se inicia con un nuevo contraste entre lo imaginario y lo real. Santiago vuelve a su casa e interpela a Barbarita con esta frase: "Soy Santiago, tu marido" (116). La esposa lo tilda de loco. La ocurrencia del narrador se debe a una frase que ha leído: "Víctor Hugo era un loco que se creía Víctor Hugo" (115). Justamente, la respuesta de Barbarita es acusarlo de locura. Pero la idea es clara: ser no es otra cosa que creer ser. O, dicho de otro modo: imaginar ser no es diferente de ser realmente. Lo que se pone en cuestión es, en efecto, el fundamento de ese ser que se afirma como real. El narrador traduce la reacción de Barbarita: "Mi marido es un loco que se cree mi marido" (117). Después, va a visitar a Laura. Lo recibe la mucama, lo hace pasar, y cuando la amada aparece, el narrador le dice: "Soy Santiago y no soy tu marido" (117). La fórmula traduce el correlato imaginario: durante toda la época especulativa, Santiago ha soñado ser el marido de Laura. La amada responde con lágrimas y con palabras que el narrador no explicita. Toman el té y se despiden: "Y me fui con esta deseada tristeza de saber que, si yo la perdí, ella también me perdió" (118). De nuevo el juego masoquista, la 
"deseada tristeza" de conocer un destino especular: a ella le pasó lo mismo, lo cual duele, pero al mismo tiempo consuela. Pero a esta altura el lector de la novela puede muy bien sospechar de la veracidad del encuentro. Y en efecto el capítulo termina: "En fin, que así es. Aunque en rigor de verdad no puedo decir que lo sea, pues no sé con certeza si este segundo episodio ha sucedido realmente" (118). Al comienzo de la novela, el protagonista especulaba; en la segunda época, separó lo imaginario de lo real; ahora está en condiciones de mezclarlo todo, de enmarañarlo, buscando esa experiencia originaria del volar, ese modo de pensamiento infantil, en el cual lo vivido no podía distinguirse de lo soñado. Ese "no saber con certeza" es lo deseado: no es una carencia, sino la potencia de lo imaginario en cuanto se vuelve inseparable de lo real, como un nacarado que cubre toda experiencia.

El policial se apodera de los últimos capítulos, con lo cual termina dándole un barniz genérico, aunque paródico, a toda la novela. Santiago descubre la infidelidad de Barbarita y maquina el asesinato de los amantes, pero falla. Finalmente, Barbarita asesina a la esposa de su amante Orlando (otro triángulo). En una escena surrealista, Santiago y Orlando son sometidos a un careo, delante del juez y de un jurado, que poca relación tiene con lo policial (Barbarita es una asesina confesa), sino más bien con la humillación de la doble infidelidad. Todo el "juicio" tiene el aire de un sueño. Pero el sueño se vuelve ya delirio o novela dentro de la novela cuando hace su aparición, como testigo, Rolando Fortuna:

${ }_{-}$¿Quién es ese hombre?

Y el juez me dijo:

-Rolando Fortuna.

Busqué, lejos, ese nombre. Lo encontré en aquellos cuentos que yo escribí, en un tiempo especulativo, para darme miedo de ser burlado y no pretender a Laura. Entonces repliqué:

-Rolando Fortuna no existe. Lo inventé yo.

-Pero puede existir, ¿iverdad? Usted daba por supuesto que sí.

-Es cierto.

-Bien. El Rolando Fortuna que está presente es una posibilidad. $\left(145^{-146}\right)^{15}$

15 Nadie ha comparado esta novela con Sin embargo fuan vivía de Alberto Vanasco, publicada en 1947, texto del que puede afirmarse que es tanto o más extraño que El pentágono. Las semejanzas rebasan lo anecdótico. Sin embargo fuan vivía es una falsa novela policial escrita en tiempo futuro y en segunda persona gramatical. Se trata de un experimento borgiano con la idea de temporalidades paralelas: lo que se trabajan son, de modo simultáneo, varias 
Volvamos a la tesis de Chejfec sobre la verdad sentimental para ver si podemos interpretarla a la luz de nuestro recorrido.

Hemos dicho más arriba que la tripartición en épocas aludía a los pasos de los razonamientos filosóficos. Hemos hablado, también, de la conciencia imaginante como opuesta a una conciencia cartesiana, es decir, racional. No habría que descartar, de ningún modo, una efectiva parodia del texto cartesiano, concretamente de la sexta de sus Meditaciones Metafísicas: no puede ser casual que, en el momento en el que Descartes debe examinar la facultad de la imaginación, recurra al ejemplo del triángulo. Descartes se esfuerza por separar intelección de imaginación: su intención es expulsar a esta última del ámbito del conocimiento (con lo cual inaugura, según Agamben, la marginación moderna de la imaginación hacia el ámbito de la irrealidad, la falsedad y la ficción). Si imagino un triángulo, razona Descartes, no solo puedo concebir una figura de tres líneas y tres ángulos, sino que además contemplo la figura con los ojos del espíritu. Es decir, la concibo y la imagino. Pero si quiero pensar un quiliógono, puedo concebir que sea una figura de mil lados, pero no puedo contemplarlo y, por lo tanto, no puedo imaginarlo (58-59). Para Sartre es, por el contrario, exactamente al revés: la imagen presenta, en contraste con la percepción, una cierta pobreza de cualidades. Recordemos la operación borgiana de reducción y abstracción de rasgos esenciales. Creemos que la tesis es convergente con esta idea sartreana de que la imagen es pobre en cualidades:

En una palabra, el objeto de la percepción desborda constantemente de la conciencia; el objeto de la imagen nunca es nada más que la conciencia que de ello se tenga; se define por esta conciencia: de una imagen no se puede aprender nada que no se sepa ya. (20-21)

La pobreza esencial de la imagen caracteriza muy bien la reticencia y austeridad del relato dibenedettiano. El carácter abstracto de El pentágono es una consecuencia de este trabajo sustractivo de la imaginación. Ahora bien, ¿cuál es el sentido de esta pobreza en las cualidades del objeto imaginado? Para Sartre, el hombre que imagina es trascendentalmente libre. Esta libertad

posibilidades para un mismo relato. Curiosamente, la novela también termina con un extraño juicio en el cual reaparece la mujer asesinada en el comienzo, lo que por otra parte podría ser una invención del protagonista (como toda la historia), que es también un escritor. Señalemos, de paso, que tanto esta novela de Vanasco como los primeros relatos de Di Benedetto han sido considerados precursores del nouveau roman. Cfr. Arce. 
implica la definición sartriana de imaginación: es la negación del mundo desde determinado punto de vista. Esta negación determinada emancipa al sujeto, que puede constituirse como conciencia imaginante, es decir, como sujeto que prefiere darse libremente un mundo irreal. En El pentágono, la negación determinada es la del mundo triangular o, si se prefiere, la del orden simbólico: lo que con Deleuze-Guattari podemos llamar las grandes unidades morales de la familia, el trabajo, el matrimonio, la sociedad (47-78). El pentágono, cierre, clausura por doble triángulo, es el modo de determinación de este negar propio de la imaginación. Irrealizar este mundo pentagonal es el modo de constitución de una conciencia que afirma su libertad.

El origen del relato dibenedettiano está en una verdad sentimental: "Cuentan que él se enamoró de una muchacha..." (25). El deseo, con todas las contradicciones que hemos examinado en clave psicoanalítica (masoquismo, sadismo, odio, celos, etc.), es por definición imposible: el mundo (el pentágono) aparece como lo que niega el deseo en el que se constituye este sujeto narrador. Negar el mundo es el trabajo que debe realizar esta conciencia para inventar un objeto para su deseo o, mejor, para volver tangible el fantasma de la amada. Santiago produce el fantasma de Laura: esto es, no quiere saber nada de la Laura real ni del mundo real. Mejor: no querer saber nada de la Laura real significa no querer saber nada del mundo real. Para Sartre, la conciencia afectiva es esencialmente conciencia imaginante, porque propone un objeto (imaginario) para una serie de estados que son del sujeto. Preferir lo imaginario a lo real es el modo de la conciencia de suturar el desencuentro (fatal) entre objeto imaginario y objeto real, o entre el sujeto y el mundo:

... la idea de que Annie [Laura en nuestro ejemplo] como realidad individual es inagotable y que, correlativamente, mi amor por ella es inagotable. El sentimiento que en todo momento se superaba a sí mismo estaba, pues, rodeado por un halo de posibilidades. Pero estas posibilidades han desaparecido, de la misma manera que el objeto real. Por una inversión esencial, es ahora el sentimiento quien produce su objeto, y Annie irreal [Laura irreal] no es más que el estricto correlativo de mis sentimientos por ella. (Sartre 188)

La imagen de Laura es, entonces, el estricto correlativo de los sentimientos de la conciencia narradora: su pobreza esencial es una síntesis en la cual la imagen encarna con precisión una serie de rasgos sentimentales que se presentan como dispersos. Es el sujeto como conciencia imaginante quien encuentra en este proceso su itinerario (lo que más arriba interpretábamos 
como nacimiento de la conciencia narradora dibenedettiana). Laura irreal, aun siendo abstracta, lejana, inasible, se ajusta más al deseo del narrador que Laura real, cuya presencia se da además en el horizonte amenazante de un mundo real (el pentágono o la unidad molar de Deleuze-Guattari). Esta es la verdad sentimental: la que encarna en una imagen un afecto que no tiene correlato en el mundo. Continúa Sartre:

No sólo se elige tal o cual imagen, se elige el estado imaginario con todo cuanto supone, no solo se huye del contenido de lo real (pobreza, amor frustrado, fracaso de nuestras empresas, etc.), sino que se huye de la forma de lo real, de su carácter de presencia, de la subordinación de nuestras conductas al objeto... (191)

Es la subjetividad la que se da su libertad al negar el mundo según su punto de vista. ${ }^{16}$ De eso se trata la novela: de la emancipación de una subjetividad sin sujeto, una subjetividad móvil, transformadora, soñadora, que se articula en una serie de imágenes que se suceden una detrás de la otra, encadenamiento de "cuentos" que tejen la novela. En rigor, nunca se trató de Laura, ni de la real ni de la imaginaria: de lo que se trataba era de esta subjetividad imaginadora, de sus modos de escapar de la cárcel pentagonal. Como dice la crítica, el sujeto dibenedettiano se fragmenta: se desdobla en la introducción, se despedaza de cuento en cuento (la reiteración del nombre, Santiago, no alcanza a conjurar la sospecha sobre su unicidad: la misma autonomía relativa de los cuentos socaba toda identidad, no solo la del protagonista sino también la del resto de los personajes). Pero lo que no dice la crítica es que hay una subjetividad que se constituye: alguien sueña, alguien imagina. En efecto, El pentágono es una novela onírica, pero su fragmentación no impide que el lector tenga la impresión de que hay una subjetividad soñadora o imaginante detrás de cada escena. Alguien sueña o imagina o delira porque, por debajo de la diversidad, la monotonía del esquema delata una subjetividad fascinada cada vez por lo mismo. O por sí misma.

16 "Basta, pues, con poder proponer la realidad como un conjunto sintético para proponerse como libre en relación a ella, y esta superación es la libertad misma, porque no se podría efectuar si no fuese libre la conciencia" (Sartre 236). 


\section{Obras citadas}

Agamben, Giorgio. Infancia e historia. Destrucción de la experiencia y origen de la historia. Buenos Aires: Adriana Hidalgo, 2007. Impreso.

Arce, Rafael. "La novela conjetural". Revista Badebec 5 (2013). http://www.badebec.org/badebec_5/sitio/index.php

Bachelard, Gaston. El agua y los sueños. México: Fondo de Cultura Económica, 1985. Impreso.

Belinsky, Jorge. Lo imaginario: un estudio. Buenos Aires: Ediciones Nueva Visión, 2007. Impreso.

Borges, Jorge Luis. "La postulación de la realidad". Obras Completas. Buenos Aires: Emecé, 2008. Impreso.

Chejfec, Sergio. Cinco. Buenos Aires: Simurg, 1998. Impreso.

Deleuze, Gilles y Félix Guattari. Mil mesetas. Capitalismo y esquizofrenia. Valencia: Pretextos, 2002. Impreso.

Descartes, René. Discurso del método. Meditaciones metafísicas. Buenos Aires: Terramar, 2004. Impreso.

Di Benedetto, Antonio. El pentágono. Buenos Aires: Anagrama, 2005. Impreso.

Feld, Claudia. "La acechanza de lo pequeño". Zama 1 (2008): 147-151. Impreso. Giordano, Alberto. "Las víctimas de la desesperación. Una aproximación al mundo de Antonio Di Benedetto". Zama 1 (2008): 154-162. Impreso.

Lacan, Jacques. "De una cuestión preliminar a todo tratamiento posible de la psicosis". Escritos 2. México: Siglo XXI, 2009. Impreso.

Néspolo, Jimena. Ejercicios de pudor. Sujeto y escritura en la narrativa de Antonio Di Benedetto. Buenos Aires: Adriana Hidalgo Editora, 2004. Impreso.

Premat, Julio. Héroes sin atributos: figuras de autor en la literatura argentina. México: Fondo de Cultura Económica, 2009. Impreso.

Premat, Julio. "Un pentágono triangular. Orígenes de la narrativa de Antonio Di Benedetto". Río de la Plata 26-27 (2004): 295-302. Impreso.

Prieto, Martín. Breve historia de la literatura argentina. Buenos Aires: Taurus, 2006. Impreso. Saer, Juan José. “Zama”. El concepto de ficción. Buenos Aires: Seix Barral, 1997. Impreso.

Sartre, Jean-Paul. Lo imaginario. Buenos Aires: Losada, 1997. Impreso.

Schvartzman, Julio. "Volverse mono. La lengua de Antonio Di Benedetto". Zama 1 (2008): 184-192. Impreso.

Varela, Fabiana Inés. "Annabella (El pentágono), de Antonio Di Benedetto: aproximaciones a una poética de la ficción". Piedra y Canto. Cuadernos del CELIM 9-10 (2003/2004): 127-140. Impreso.

Verdevoye, Paul. "Antonio Di Benedetto". Antología de la narrativa hispanoamericana 1940-1970. Tomo 1. Madrid: Gredos, 1979. Impreso. 